\title{
The Influence of Aluminium-Silicon Alloy on ZDDP Tribofilm Formation on the Counter-Surface
}

\author{
Yasunori Shimizu $^{1,2} \cdot$ Hugh A. Spikes ${ }^{1}$
}

Received: 5 April 2017/Accepted: 22 August 2017/Published online: 8 September 2017

(c) The Author(s) 2017. This article is an open access publication

\begin{abstract}
In order to reduce vehicle weight and thus improve fuel economy, aluminium (Al) alloys have been increasingly adopted as contact surfaces such as piston skirts and cylinder liners in current engines. In general, hypereutectic Al-Si alloys are used, in which hard silicon grains are embedded in a softer $\mathrm{Al}-\mathrm{Si}$ single phase matrix. It is reported that after rubbing, the matrix is removed to leave silicon grains protruding from the surface. However, the response of the counter-surface by these silicon grains is rarely investigated. In this study, mini traction machinespace layer imaging (MTM-SLIM) has been used to monitor tribofilm formation in situ and investigate the evolution of both surfaces in the contact of a steel ball on an $\mathrm{Al}-\mathrm{Si}$ disc lubricated by ZDDP solution. In low-load conditions, the top layer of aluminium on the $\mathrm{Al}-\mathrm{Si}$ disc is removed physically to leave silicon grains protruding from the surface, while ZDDP tribofilm pads are formed mainly on the grains. On the counter-surface (steel ball), ZDDP tribofilms are formed and build up with no wear scars. In high-load conditions, deep gaps are observed to form initially round the silicon grains on the disc. During rubbing, these become shallower, while the silicon grains start to protrude. On the steel ball, ZDDP tribofilm is generated initially over the whole rubbing track, but then the tribofilm in the middle of the track is almost completely removed by
\end{abstract}

Yasunori Shimizu

yasunori.shimizu@idemitsu.com

1 Tribology Group, Department of Mechanical Engineering, Imperial College London, South Kensington, Exhibition Road, London SW7 2AZ, UK

2 Lubricants Research Laboratory, Idemitsu Kosan Co., Ltd, 24-4 Anesakikaigan, Ichihara-Shi, Chiba 299-0107, Japan rubbing against the protruding silicon grains. Wear of the underlying steel surface then ensues.

Keywords Zinc dialkyldithiophosphate $\cdot$ ZDDP $\cdot$ ZnDTP . Tribofilm · Wear · Antiwear - Aluminium alloy $\cdot$ MTM . SLIM

\section{Introduction}

Despite considerable improvements in recent years, there is still great concern to further reduce the fuel consumption of internal combustion engines in passenger vehicles. In engine development, the compression ratio and the specific power of engines have been progressively increased [1, 2] resulting in higher cylinder liner temperatures near the combustion chamber, especially at top dead centre. This produces conditions that are more likely to produce wear and scuffing of piston ring-cylinder liner contacts [3]. In addition, non-ferrous materials have been introduced in both engines and transmissions to reduce vehicle weight and thus improve fuel economy. In some cases, these materials are used as one of the rubbing components in tribological contacts, for example in piston rings and in cylinder liners, and in the latter case, hypereutectic aluminium-silicon alloys ( $\mathrm{Al}-\mathrm{Si}$ alloys), which provide reasonable antiwear performance, have been increasingly adopted [4-6]. Therefore, engine oil formulations are required to show good antiwear and antiseizure performance under these more severe conditions with $\mathrm{Al}-\mathrm{Si}$ alloys as well as with ferrous materials.

Since zinc dialkyldithiophosphate (ZDDP) is the most widely used antiwear additive in engine oils, many researchers have studied the antiwear and antiseizure performance of Al-Si alloys with ZDDP-containing oils and 
investigated tribofilms formed on their surfaces. Nicholls et al. [7, 8] investigated ZDDP tribofilm formation on AlSi alloy (A390). They reported that after rubbing, silicon grains protruded up to $150 \mathrm{~nm}$ above the aluminium surface. Using atomic force microscopy (AFM), they found that these silicon grains were covered by antiwear pads of thickness between 30 and $100 \mathrm{~nm}$. The ZDDP tribofilm morphology on the silicon grains was very similar to that found on steel surfaces [9]. X-ray photoelectron emission spectroscopy (X-PEEM) and X-ray absorption near edge structure (XANES) analyses showed that polyphosphate film as zinc polyphosphate existed on both the $\mathrm{Al}$ matrix and the Si grains. However, on the surrounding aluminium matrix, no antiwear pads were observed though polyphosphate glass spectra indicative of ZDDP tribofilms were obtained. The authors suggested that during rubbing, the top layer of aluminium is removed physically while silicon grains remain in the surface, and ZDDP tribofilm pads are built up on the grains. Neville et al. also investigated the ZDDP tribofilm formation on $\mathrm{Al}-\mathrm{Si}$ alloy with lubricants containing both molybdenum dialkyldithiocarbamate (MoDTC) and ZDDP [10]. From their research, different tribofilm formation schemes were found depending on the MoDTC concentration. One result using a MoDTC content lubricant $(0.22 \mathrm{wt} \% \mathrm{Mo})$ showed similar behaviour to the findings of Nicholls et al. [7]; ZDDP tribofilms formed mainly on the protruded silicon grains after aluminium was removed.

Although these authors found that silicon grains alone remain in the surface after aluminium is removed physically during rubbing, the effect of these protruding silicon grains on the ferrous counter-surface has rarely been considered. This is important since clearly a protective tribofilm is required on at least one of the pair of rubbing surfaces in order to provide protection against wear and seizure.

The mini traction machine-space layer imaging (MTMSLIM), PCS Instrument is a well-known and useful method to monitor ZDDP tribofilm growth in situ, and its use to study the kinetics of ZDDP tribofilm growth has been reported widely [11-22]. In this paper, MTM-SLIM has been used to monitor ZDDP tribofilm formation and wear on the ferrous counter-surface rubbed against Al-Si alloys. This has been accompanied by optical and analytical investigation of both surfaces after rubbing.

\section{Test Methods}

The experiments in this work are conducted in a MTMSLIM ball on disc test rig as shown in Fig. 1. In the normal operation of this rig, a 19.05-mm-diameter ball made of AISI $52100(\mathrm{Ra}=0.02 \mu \mathrm{m})$ is loaded against a flat surface

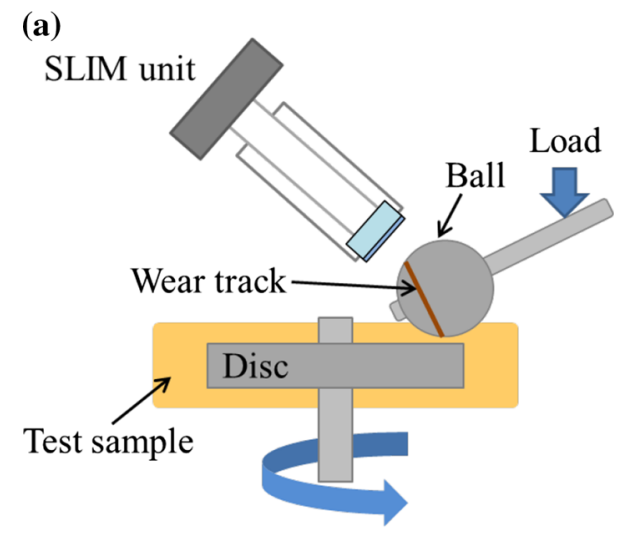

(b)

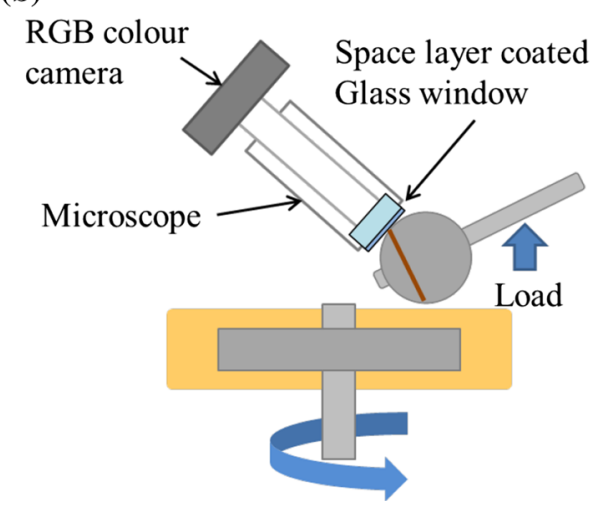

Fig. 1 a Schematic image of MTM-SLIM during a friction test, b schematic image of MTM-SLIM while capturing an image

of a 46-mm-diameter steel disc or Al-Si disc (AISI 52100, $\mathrm{Ra}=0.01 \mu \mathrm{m} \quad$ or $\mathrm{A} 390, \quad \mathrm{Ra}=0.05 \mu \mathrm{m}) \quad$ which is immersed in the oil sample. The ball and the disc are continuously driven by separate electric motors, and tribofilms can form on both rubbing surfaces. At set intervals, motion is halted and the stationary ball is raised and loaded upward against a coated glass window (Fig. 1b). An interference image of the contact between the ball and the glass window is captured by a camera in order to record tribofilm formation on the ball.

Table 1 shows the main test conditions in this study. The load, the mean speed and the oil temperature were kept constant during all tests, at 5 or $20 \mathrm{~N}, 160 \mathrm{~mm} / \mathrm{s}$ and $130{ }^{\circ} \mathrm{C}$, respectively. The maximum contact pressure at $5 \mathrm{~N}$ between a steel ball and a steel disc is almost same as the one at $20 \mathrm{~N}$ between a steel ball and an Al-Si disc. Two SRR conditions were studied, $100 \%$ SRR and $201 \%$ SRR, where SRR is defined by Eq. 1.

$\mathrm{SRR}=\left|u_{\mathrm{D}}-u_{\mathrm{B}}\right| / U$

where $u_{\mathrm{B}}$ and $u_{\mathrm{D}}$ are the speeds of the ball and disc surfaces relative to the contact and $U$ is the mean or entrainment speed, $\left(u_{\mathrm{B}}+u_{\mathrm{D}}\right) / 2$. When the SRR is $100 \%$, tests are performed under mixed rolling-sliding conditions with the 
Table 1 Test conditions

\begin{tabular}{|c|c|c|c|c|c|c|c|c|}
\hline Ball & \multicolumn{8}{|c|}{ AISI 52100} \\
\hline Disc & \multicolumn{4}{|c|}{ AISI 52100} & \multicolumn{4}{|l|}{ A390 } \\
\hline Load $(\mathrm{N})$ & 5 & & 20 & & 5 & & 20 & \\
\hline Maximum Hertzian pressure (GPa) & 0.52 & & 0.83 & & 0.34 & & 0.55 & \\
\hline $\operatorname{SRR}(\%)$ & 100 & 201 & 100 & 201 & 100 & 201 & 100 & 201 \\
\hline Ball speed $(\mathrm{mm} / \mathrm{s})$ & 80.0 & -0.8 & 80.0 & -0.8 & 80.0 & -0.8 & 80.0 & -0.8 \\
\hline Disc speed $(\mathrm{mm} / \mathrm{s})$ & 240.0 & 320.8 & 240.0 & 320.8 & 240.0 & 320.8 & 240.0 & 320.8 \\
\hline Mean speed $(\mathrm{mm} / \mathrm{s})$ & \multicolumn{8}{|c|}{ Always 160} \\
\hline Temperature $\left({ }^{\circ} \mathrm{C}\right)$ & \multicolumn{8}{|c|}{ Always 130} \\
\hline
\end{tabular}

ball and the disc rotating in the same direction (co-rotating mixed sliding-rolling), the ball surface moving more slowly than the disc surface. An SRR of $200 \%$ corresponds to pure sliding (one surface stationary). When the SRR is $201 \%$, the ball and the disc are rotating in opposite directions (contra-rotating mixed sliding-rolling) with the ball surface moving very slowly.

After rubbing, the steel ball and Al-Si alloy discs were subjected to various methods of surface analysis. Before the surface investigation, the specimens were rinsed and cleaned with analytical reagent toluene in an ultrasonic bath for $3 \mathrm{~min}$.

For the Al-Si alloy discs, optical images were captured using a digital microscope (Hirox RH-2000). AFM was then used to analyse worn tracks on the discs. The apparatus was a WITec alpha 300A, and the cantilever was a WITec AFM arrow cantilever reflex-coated. Scanning electron microscope and energy-dispersive X-ray spectroscopy (SEM-EDX) were used to analyse the tribofilms formed on the surface of the steel balls. An SEM, HITACHI S-3400N, was used to capture high-resolution images of tribofilm surface topography and EDX; an Oxford X-ray System, INCA, was used to analyse the chemical composition of the tribofilms. In this study, the accelerating voltage was $5 \mathrm{keV}$ and the working distance was $10 \mathrm{~mm} \pm 1 \mathrm{~mm}$. After that, in order to measure the ZDDP tribofilm thickness, the AFM-EDTA (ethylenediaminetetraacetic acid, disodium salt) method was employed [16]. For the steel balls, SEM-EDX was used after capturing optical images using the digital microscope.

\section{Test Materials}

All lubricant test samples were solutions of a ZDDP in polyalphaolefin base oil at a concentration that corresponded to $0.08 \mathrm{wt} \%$ of phosphorus. No other additives were present. The ZDDP employed was a C8 primary type, and the base oil had a kinematic viscosity of $4.1 \mathrm{~mm}^{2} / \mathrm{s}$ at $100{ }^{\circ} \mathrm{C}, 2.6 \mathrm{~mm}^{2} / \mathrm{s}$ at $130{ }^{\circ} \mathrm{C}$ and a viscosity index of 124 .

The steel ball and disc were both AISI 52100 steel (1\% Cr) with hardness 750-770 and 800-920 HV, respectively.
They were provided by PCS Instruments. The Al-Si disc was A390 alloy consisting of $16.0-18.0 \%$ silicon, $4.0-5.0 \%$ copper and $0.45-0.65 \%$ magnesium etc., with the hypereutectoid silicon distributed as individual $\mathrm{Si}$ particles (Fig. 2). Hardness measurements on the $\mathrm{Al}$ matrix and $\mathrm{Si}$ grains indicated 170 and $190 \mathrm{HV}$, respectively (measured with Mitutoyo Autovick). The former is somewhat higher than the hardness value of the $\mathrm{Al}$ matrix measured by Chen and Alpas of about $85 \mathrm{HV}$ for Si $18.5 \%$ alloy [23-25]. It is recognised that this value for $\mathrm{Si}$ grains is probably not the latter's intrinsic hardness and may reflect in part the supporting matrix. It was noted that measurements on grains in regions of high grain density gave rather higher values than those of isolated grains. Nanoindentation measurements in the literature suggest hardness values for silicon particles in $\mathrm{Al}-\mathrm{Si}$ alloys of around $1000 \mathrm{HV}$ [26, 27], which is similar to value for bulk silicon.

\section{Test Results}

\subsection{MTM-SLIM Results}

The ZDDP tribofilms formed on steel balls after rubbing against $\mathrm{Al}-\mathrm{Si}$ alloy discs and steel discs were compared. (Some results were obtained in previous research [21].) Figures 3 and 4 show interference images on the MTM steel balls at 5 and $20 \mathrm{~N}$, respectively, while Fig. 5 shows mean film thicknesses at the middle of the worn area on the balls which were calculated from these interference images.

At $5 \mathrm{~N}$ using both steel discs and $\mathrm{Al}-\mathrm{Si}$ discs, it can be seen that the colour of the images gradually changes with rubbing time (Figs. 4, 5a). This indicates that ZDDP tribofilms are formed and build up progressively on the rubbed tracks on the steel balls during rubbing although tribofilm formation speeds are different. This tribofilm forming process is also observed at $20 \mathrm{~N}$ using steel discs in Fig. 4. However, when using an Al-Si disc, the tribofilm develops over the first 15 min of rubbing but then diminishes. This is clearly seen in the microscope image (Fig. 6) 

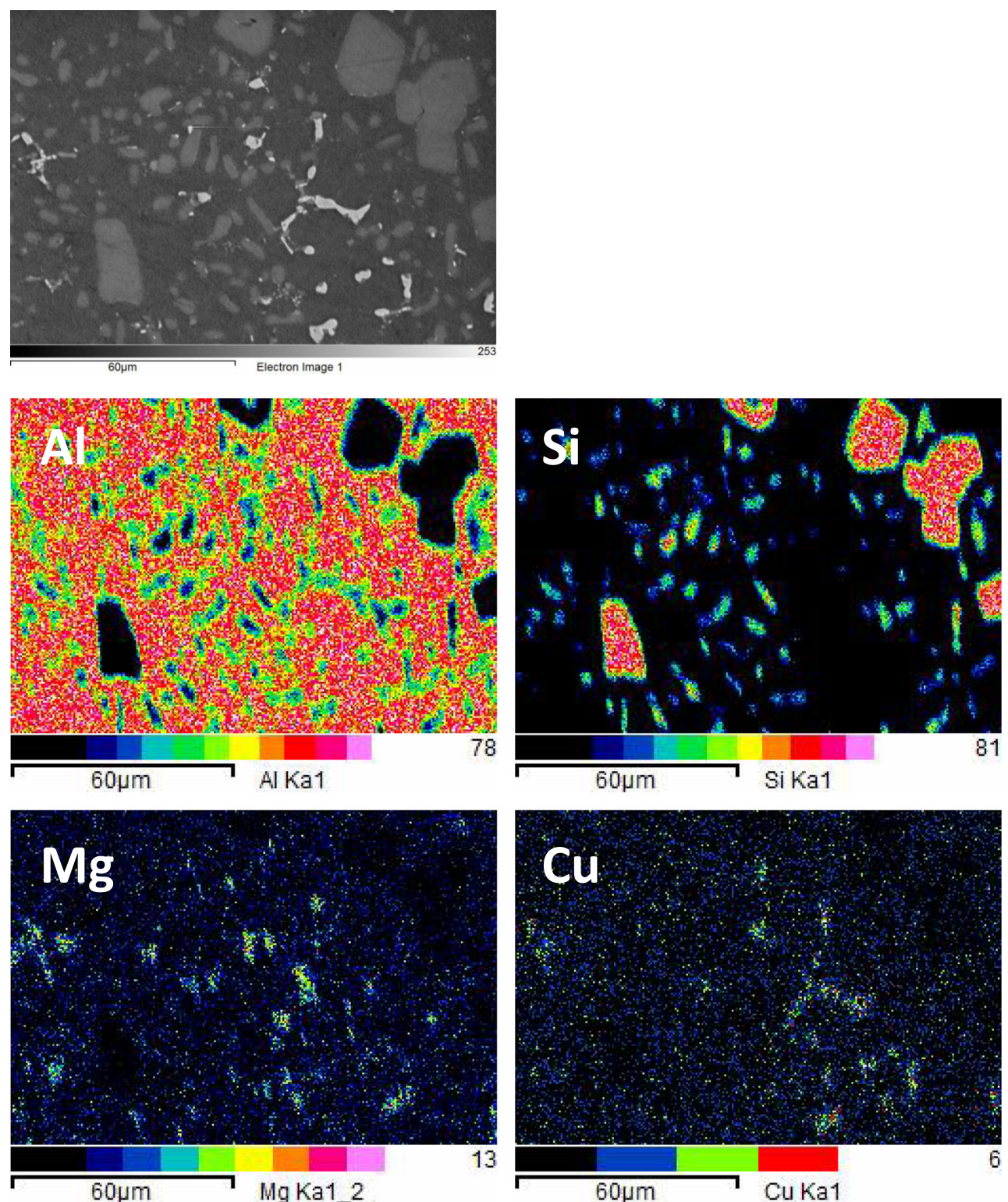

Fig. 2 SEM-EDX results from an unrubbed Al-Si disc

and in Fig. 5b where the mean tribofilm thickness over the central region of the track is plotted against rubbing times.

At $5 \mathrm{~N}$ load after rubbing for $90 \mathrm{~min}$, the width of the track on the ball for the steel/steel combination (Fig. 3) was $126 \mu \mathrm{m}$, while at $20 \mathrm{~N}$ as shown in Fig. 4, it was $199 \mu \mathrm{m}$. These compare with the theoretical Hertz diameters based on supplied elastic modulus data of 134 and $214 \mu \mathrm{m}$, respectively. The results confirm that no wear occurs on the ball and disc surfaces since the track widths were slightly below the theoretical Hertz values. For the $\mathrm{Al}-\mathrm{Si}$ disc on steel ball, the width of the track on the ball at $5 \mathrm{~N}$ after rubbing for $90 \mathrm{~min}$ was $168 \mu \mathrm{m}$, and it was also almost same as the theoretical diameter $167 \mu \mathrm{m}$. However, at $20 \mathrm{~N}$, it exceeded the width of the SLIM image and reached to $360 \mu \mathrm{m}$, which is about 1.4 times larger than the theoretical diameter of $264 \mu \mathrm{m}$ (Fig. 6) indicative of wear on one or both of the surfaces. Figure 7 shows 2D profiles obtained using SWLI (scanning white-light interferometry, Wyko NT9100) of the steel balls rubbed against Al-Si and steel discs after tribofilm removal by EDTA at the end of 90 min rubbing tests at $20 \mathrm{~N}$. For the ball rubbed against the steel disc, no wear is observed on the track, but for the ball rubbed against the $\mathrm{Al}-\mathrm{Si}$ disc, although this contact pressure was lower than the one between a steel ball and a steel disc, a wear track, $1.8 \mu \mathrm{m}$ in depth, is observed in the central region of the track corresponding to the region where tribofilm has been removed during rubbing. 


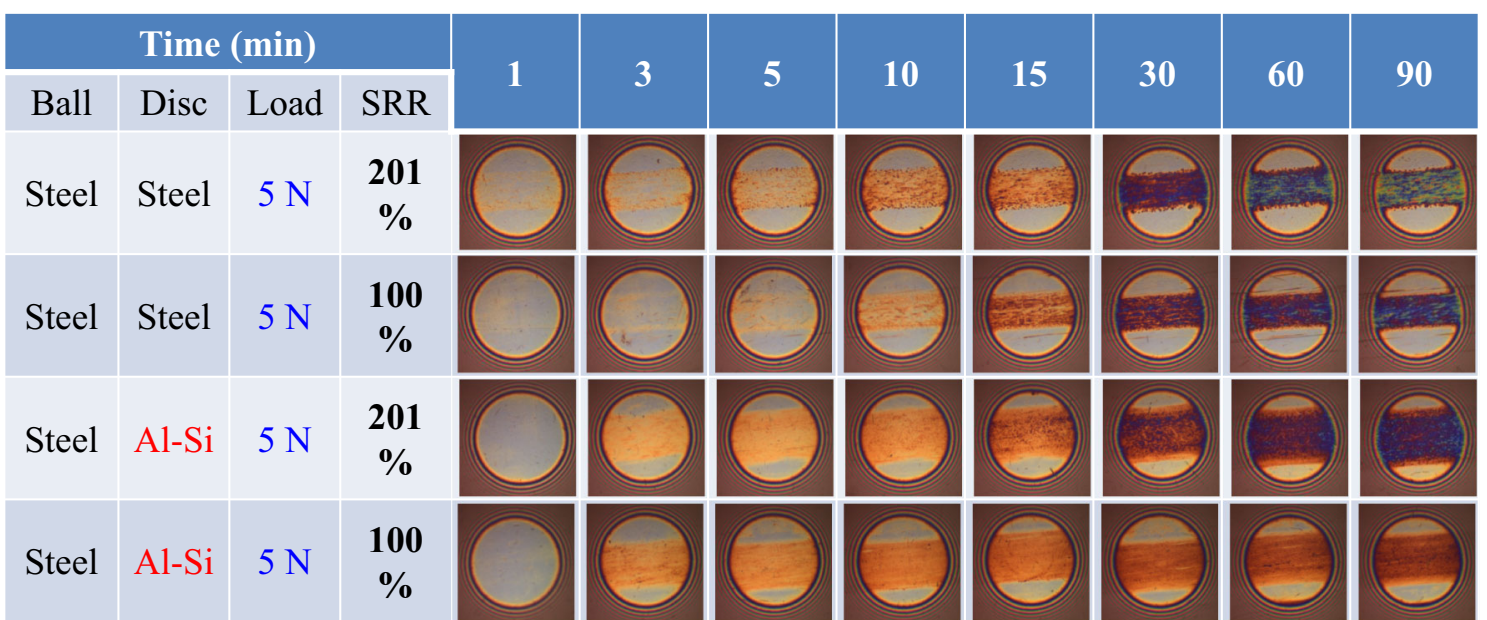

Fig. 3 Series of SLIM images of the steel ball under $5 \mathrm{~N}$

\begin{tabular}{|c|c|c|c|c|c|c|c|c|c|c|c|}
\hline \multicolumn{4}{|c|}{ Time (min) } & 1 & 2 & 5 & 10 & $1 F$ & 20 & 60 & $n$ \\
\hline Ball & Disc & Load & SRR & 1 & $\boldsymbol{J}$ & 2 & 10 & 10 & 30 & 00 & 90 \\
\hline Steel & Steel & $20 \mathrm{~N}$ & $\begin{array}{c}201 \\
\%\end{array}$ & & & & & & & & \\
\hline Steel & Steel & $20 \mathrm{~N}$ & $\begin{array}{c}100 \\
\%\end{array}$ & & & & & & & & \\
\hline Steel & $\mathrm{Al}-\mathrm{Si}$ & $20 \mathrm{~N}$ & $\begin{array}{c}201 \\
\%\end{array}$ & & & & & & & & \\
\hline Steel & $\mathrm{Al}-\mathrm{Si}$ & $20 \mathrm{~N}$ & $\begin{array}{c}100 \\
\%\end{array}$ & & & & & & & & 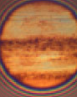 \\
\hline
\end{tabular}

Fig. 4 Series of SLIM images of the steel ball under $20 \mathrm{~N}$

Fig. 5 Mean film thickness at the middle of the worn area on the ball at a $5 \mathrm{~N}$ and $\mathbf{b} 20 \mathrm{~N}$

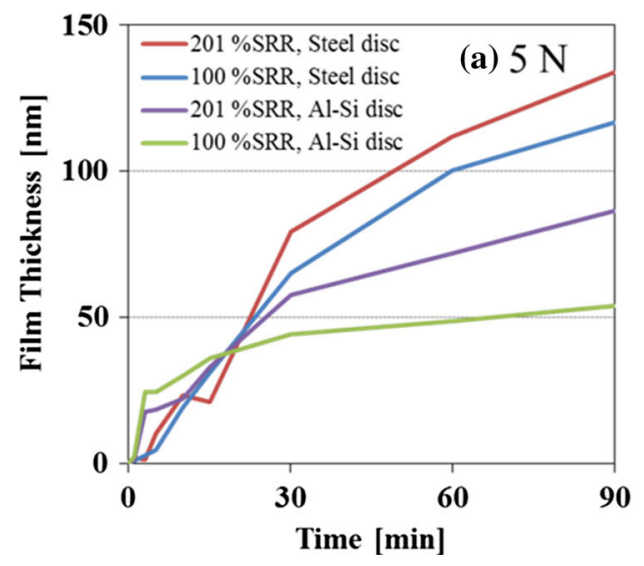

As mentioned in the test conditions section (and also indicated by the similar track widths in Figs. 3, 4), the maximum contact pressure at $5 \mathrm{~N}$ between a steel ball and a steel disc is similar to the one at $20 \mathrm{~N}$ between a steel ball and an Al-Si disc. However, since tribofilm removal was observed only when Al-Si discs were used, this suggests that silicon grains are responsible the tribofilm removal from the steel ball and also wear of the steel. 


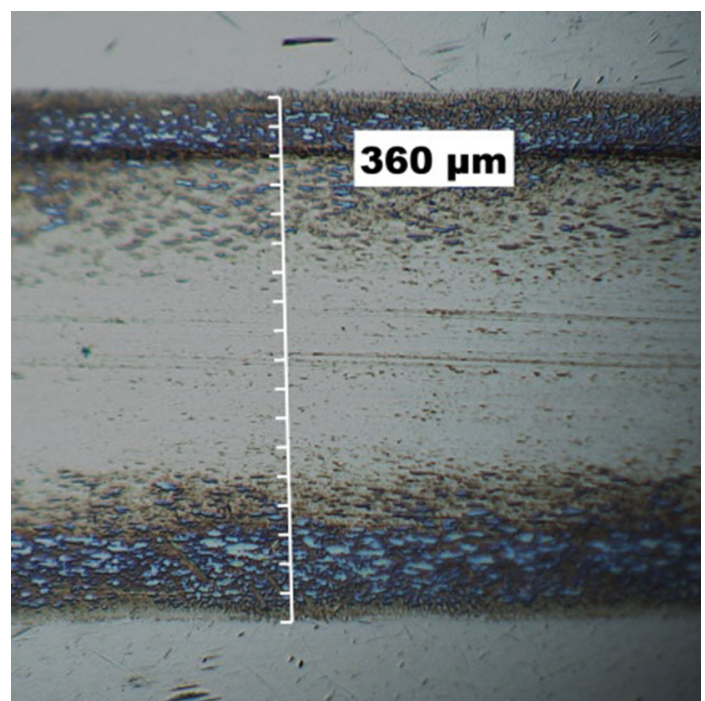

Fig. 6 Microscope image on the ball rubbed against an Al-Si disc at $90 \mathrm{~min}$ in $20 \mathrm{~N}, 201 \% \mathrm{SRR}$

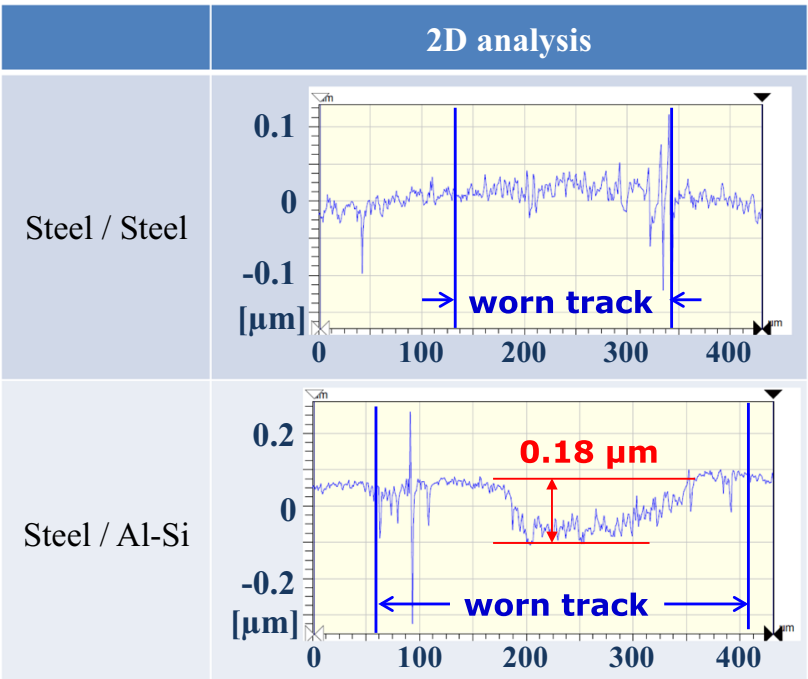

Fig. 7 Profiles of steel balls rubbed against a steel disc and an $\mathrm{Al}-\mathrm{Si}$ disc for $90 \mathrm{~min}$ at $20 \mathrm{~N}, 201 \% \mathrm{SRR}$

\subsection{Surface Analysis on Steel Balls}

Figure 8 shows the results of SEM-EDX of steel balls after at 1 and 15 min tests in which the ball was rubbed against an Al-Si disc at $201 \%$ SRR and $20 \mathrm{~N}$. For the spectra obtained using EDX, Zn and P, which are key elements of ZDDP tribofilms, are observed across the whole rubbed track in both tests. Interestingly, $\mathrm{Al}$ is also detected. Figure 9 shows the results of SEM-EDX after a 90-min test. This is from the ball whose optical image is shown in Fig. 6 and compares with EDX intensities near the edge (a) where SLIM shows the presence of a tribofilm with the middle of the worn track (b) where the film is largely removed. For the result of the darker area at the edge, $\mathrm{Al}$ is

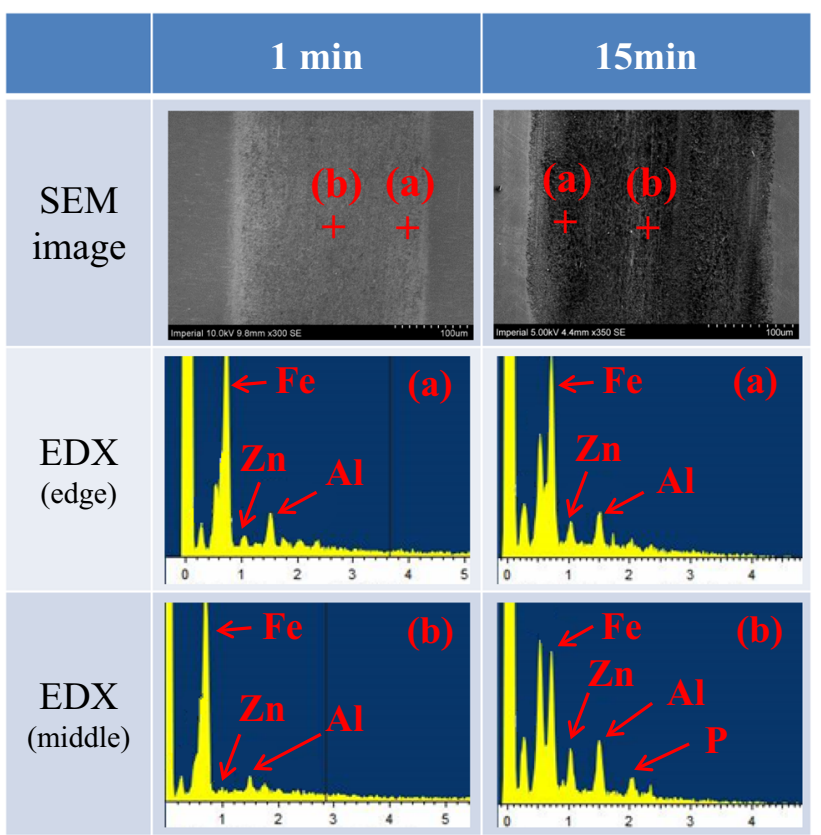

Fig. 8 SEM-EDX results of the steel ball rubbed with Al-Si disc for 1 and $15 \mathrm{~min}$ in $20 \mathrm{~N}, 201 \% \mathrm{SRR}, a$ is at edge of track, $b$ is at middle of track
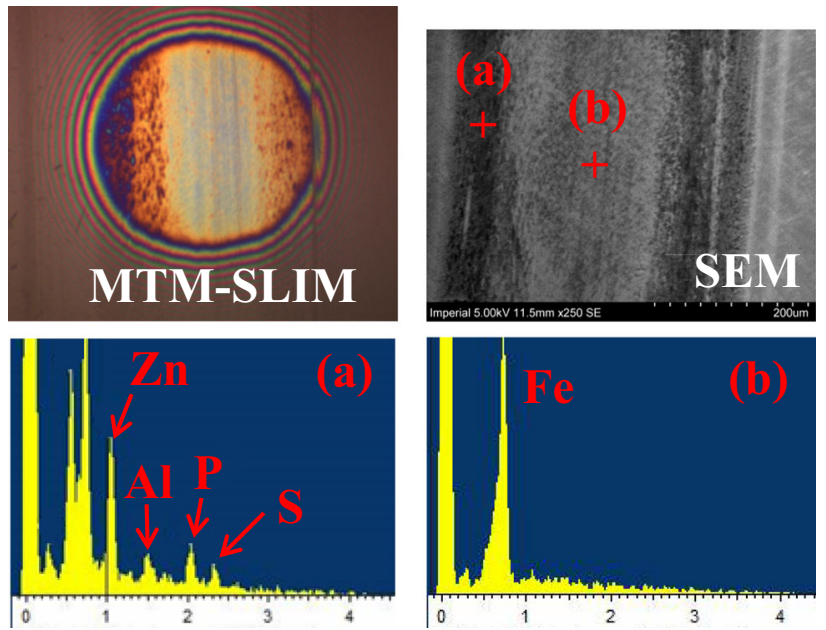

Fig. 9 SEM-EDX results of the steel ball rubbed with Al-Si disc for $90 \mathrm{~min}$ at $20 \mathrm{~N}, 201 \%$ SRR, $a$ is at edge of track, $b$ is at the middle of track

observed as well as $\mathrm{Zn}, \mathrm{P}$ and $\mathrm{S}$. In contrast to the results in Fig. 8, no elements from ZDDP and Al-Si alloy are observed in the middle of the track.

From the results obtained using MTM-SLIM and SEMEDX, it can be concluded that when a steel ball is rubbed against an $\mathrm{Al}-\mathrm{Si}$ disc at $20 \mathrm{~N}$ load, ZDDP tribofilm is created on the whole rubbing track on the steel ball at the beginning of the test, but the tribofilm in the middle of the track is then removed, although the tribofilm near the edges remains during further rubbing. In addition, aluminium is 
transferred from the Al-Si disc to the steel ball during the test.

\subsection{Surface Analysis of Al-Si Discs}

Figure 10 shows a microscope image and EDX analysis of the Al-Si disc after 90 min rubbing at $5 \mathrm{~N}$ and 100\% SRR, a condition that showed tribofilm build-up (Fig. 3). An AFM topography image is also shown in Fig. 10 from a grain inside the rubbed track. It is observed that the ZDDP tribofilm pads exist on the silicon grains, as reported by Nicholls et al. [7]. From 2D line profiles before and after tribofilm removal by EDTA solution (Fig. 11), the ZDDP film thickness on the $\mathrm{Si}$ grain shown can be determined to be a maximum of about $150 \mathrm{~nm}$ (Fig. 12). Also, after the tribofilm removal, it can be seen that the surface of the silicon grain protrudes $90 \mathrm{~nm}$ above the aluminium surface.

No significant difference in the topography on the $\mathrm{Al}$ matrix between before and after tribofilm removed by EDTA solution was observed, suggesting that little if any ZDDP tribofilm is formed on the $\mathrm{Al}$ matrix. In order to confirm this, the rubbed and non-rubbed areas were compared (Fig. 13). Tribofilm up to $80 \mathrm{~nm}$ thickness is present on the rubbed Si grain, but no clear film was observed on Al matrix within the rubbed track. Figure 14 shows a microscope image and EDX and AFM results after $90 \mathrm{~min}$ rubbing at $20 \mathrm{~N}$. The surface of the silicon grain including ZDDP tribofilm protrudes $150 \mathrm{~nm}$ from the aluminium surface. No significant change of the grain surface was observed after tribofilm removed by EDTA solution, suggesting that although $\mathrm{Zn}$ is detected in EDX, very little, if any, of this film was present on the protruding silicon grains and Al matrix after testing at high load.

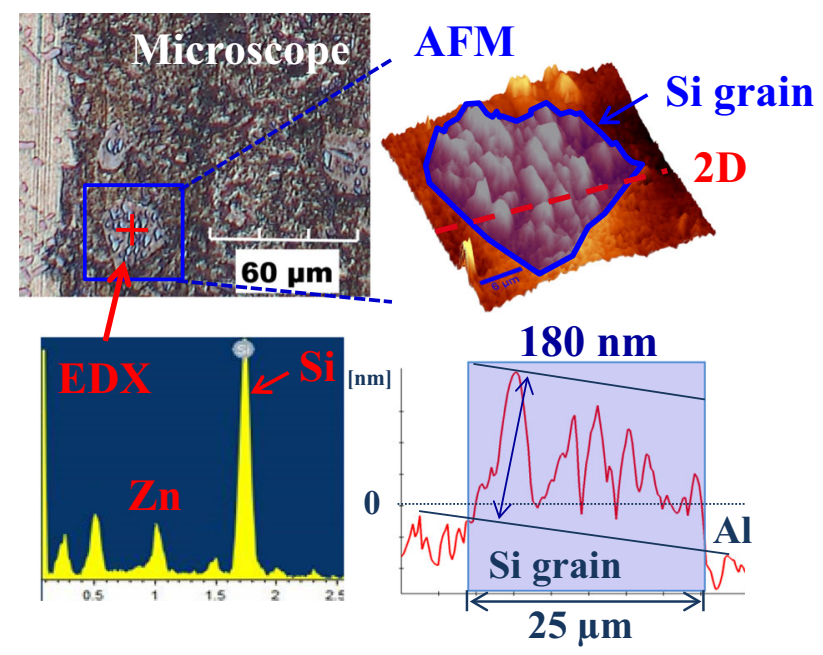

Fig. 10 Optical, EDX and AFM results from the Al-Si disc at the end of test. Test duration: $90 \mathrm{~min}$; Load: $5 \mathrm{~N}$; SRR: 100\%: on the worn track

\section{Tribofilms removed by EDTA}
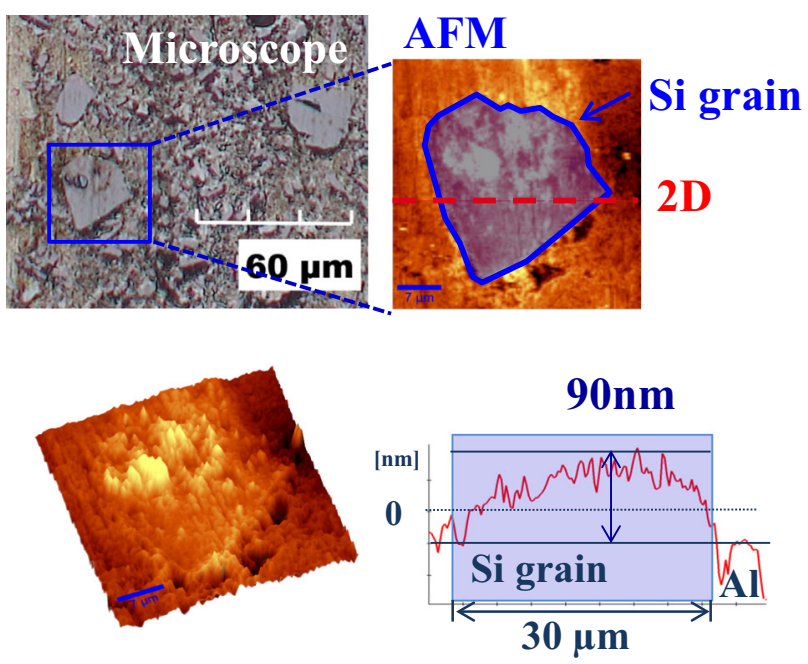

Fig. 11 AFM results on the worn track from the Al-Si disc after tribofilm removal by EDTA. Test duration: $90 \mathrm{~min}$; Load: $5 \mathrm{~N}$; SRR: $100 \%$

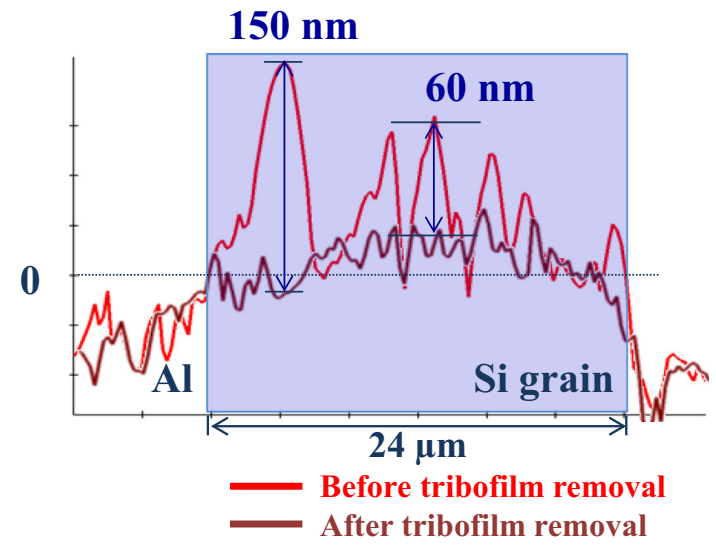

Fig. 12 Comparison of AFM results before (Fig. 10) and after (Fig. 11) tribofilm removal by EDTA. Test duration: 90 min; Load: $5 \mathrm{~N}$; SRR: $100 \%$

Figure 15 compares AFM images of Al-Si discs after different rubbing times at $20 \mathrm{~N}$ and $201 \%$ SRR, which condition showed tribofilm build-up and then removal with rubbing time (Fig. 3). No tribofilm pads are observed on the silicon grains. This suggests that the test conditions are too severe to build up tribofilm pads.

Figure 15 also shows 2D profiles across an individual Si grain. After only 1 min rubbing at $201 \%$ SRR, deep gaps develop between the aluminium matrix and the silicon grains. These have maximum depth $600 \mathrm{~nm}$ below the surfaces of the aluminium, which, after this short rubbing time is almost level with the top of the silicon grains. After 15 min rubbing, these grooves are shallower, at $190 \mathrm{~nm}$, while the silicon grain protrudes $210 \mathrm{~nm}$ above the aluminium surface. After $90 \mathrm{~min}$ rubbing, the grooves have 
Fig. 13 Optical and AFM results across the edge of the worn track from the $\mathrm{Al}-\mathrm{Si}$ disc at the end of test. Test duration: 90 min; Load: 5 N; SRR: 100\%

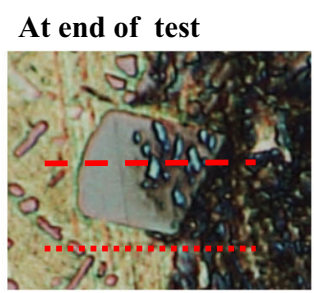

Tribofilms removed by EDTA
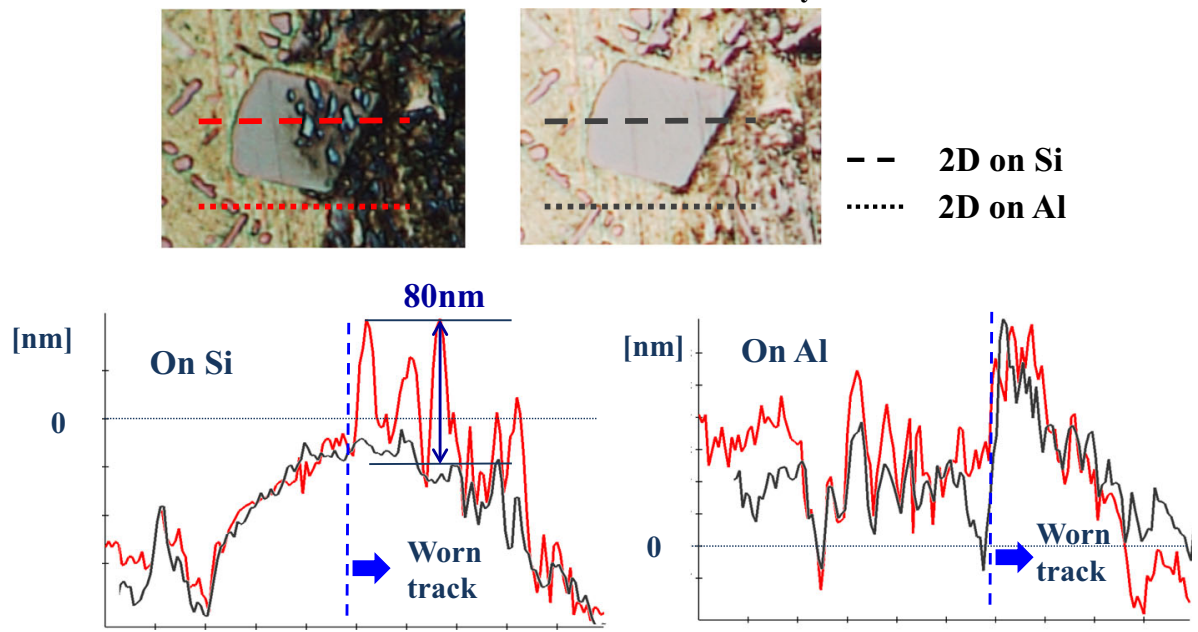

- Before tribofilm removal

After tribofilm removal

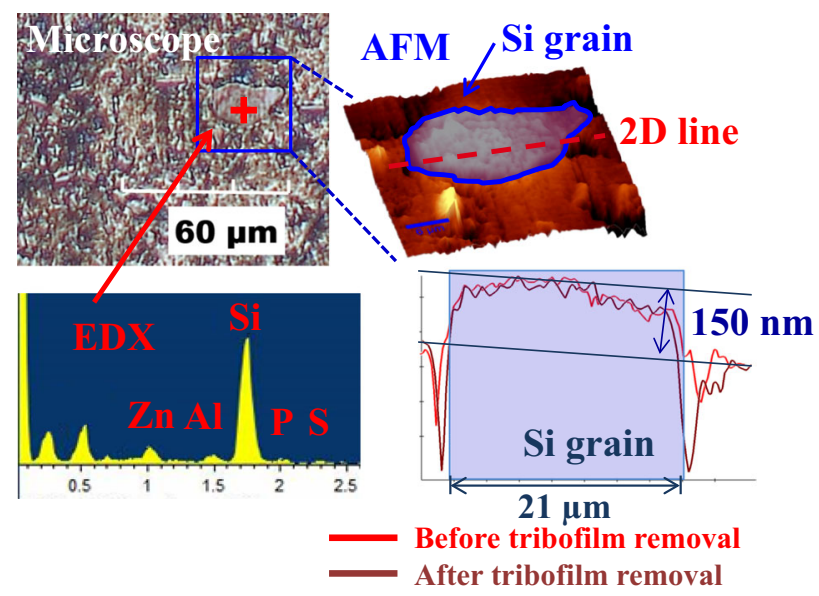

Fig. 14 Optical, EDX and AFM results from the Al-Si disc at the end of test. Test duration: 90 min; Load: 20 N; SRR: $100 \%$

disappeared and the grains stand ca. $230 \mathrm{~nm}$ above the $\mathrm{Al}$ matrix. At 15 and $90 \mathrm{~min}$, the microscope images show some cracks on the silicon grains. From the changes of groove depth, it is suggested that aluminium matrix near the silicon grain may be transferred and fill the gaps developed between grain and matrix during initial sliding.

Figure 16 shows EDX results at different test times in $20 \mathrm{~N}$ and $201 \%$ SRR from the same specimens as shown in Fig. 15. After 1 min of rubbing, MTM-SLIM shows that ZDDP antiwear tribofilm is formed on the steel ball. However, no tribofilm is observed on the silicon grains and little on the surrounding aluminium matrix. However, after $15 \mathrm{~min}$, ZDDP tribofilm is observed on the silicon grains as well as on aluminium matrix and the steel ball. After 90 min rubbing, $\mathrm{Zn}$ is still detected on both silicon and aluminium, but the intensity of $\mathrm{Zn}$ on silicon is weaker than that on aluminium although the intensities on both silicon and aluminium are almost equal to the ones at $15 \mathrm{~min}$.

In order to support these results, the AFM-EDTA method was employed. Figures 17 and 18 show the AFM topography measurements of the $\mathrm{Al}-\mathrm{Si}$ disc after 15 and 90 min rubbing, respectively. After $15 \mathrm{~min}$, the ZDDP tribofilm thickness on the silicon grain is about $40 \mathrm{~nm}$ based on comparison with the 2D line results before and after tribofilm removal by EDTA. After $90 \mathrm{~min}$, it is about $10 \mathrm{~nm}$ on the worn track (Fig. 18a) and shows similarity to the result at $90 \mathrm{~min}$ in $20 \mathrm{~N}, 100 \%$ SRR (Fig. 14). For the result on the $\mathrm{Al}$ matrix near the edge of the worn area (Fig. 18b), no significant change of the surface is observed after tribofilm removal by EDTA. Less ZDDP tribofilm builds up on both $\mathrm{Si}$ grains and $\mathrm{Al}$ matrix although $\mathrm{Zn}$ is detected in EDX. It can be inferred that the ZDDP tribofilms on both silicon grain and steel ball are removed during further rubbing. It should be noted that this and the previously described AFM measurements are based on individual Si grains so the actual film thicknesses obtained are representative rather than statistical averages. Many grains would have to be analysed to derive accurate mean values.

From the results of the analysis for the Al-Si discs, it can be concluded that ZDDP tribofilm pads form only on silicon grains under low-load condition; on the other hand, under high-load conditions, tribofilms are formed on the disc at the beginning of the test but these are removed during the further rubbing. Over the same period, ZDDP tribofilms on the steel ball are also removed by rubbing with the protruded silicon grains. 




Fig. 15 AFM results of Al-Si disc at 1, 15 and $90 \mathrm{~min}$ in $20 \mathrm{~N}, 201 \%$ SRR

Fig. 16 EDX results of $\mathrm{Al}-\mathrm{Si}$ disc at 1,15 and $90 \mathrm{~min}$ in 20 N, 201\% SRR

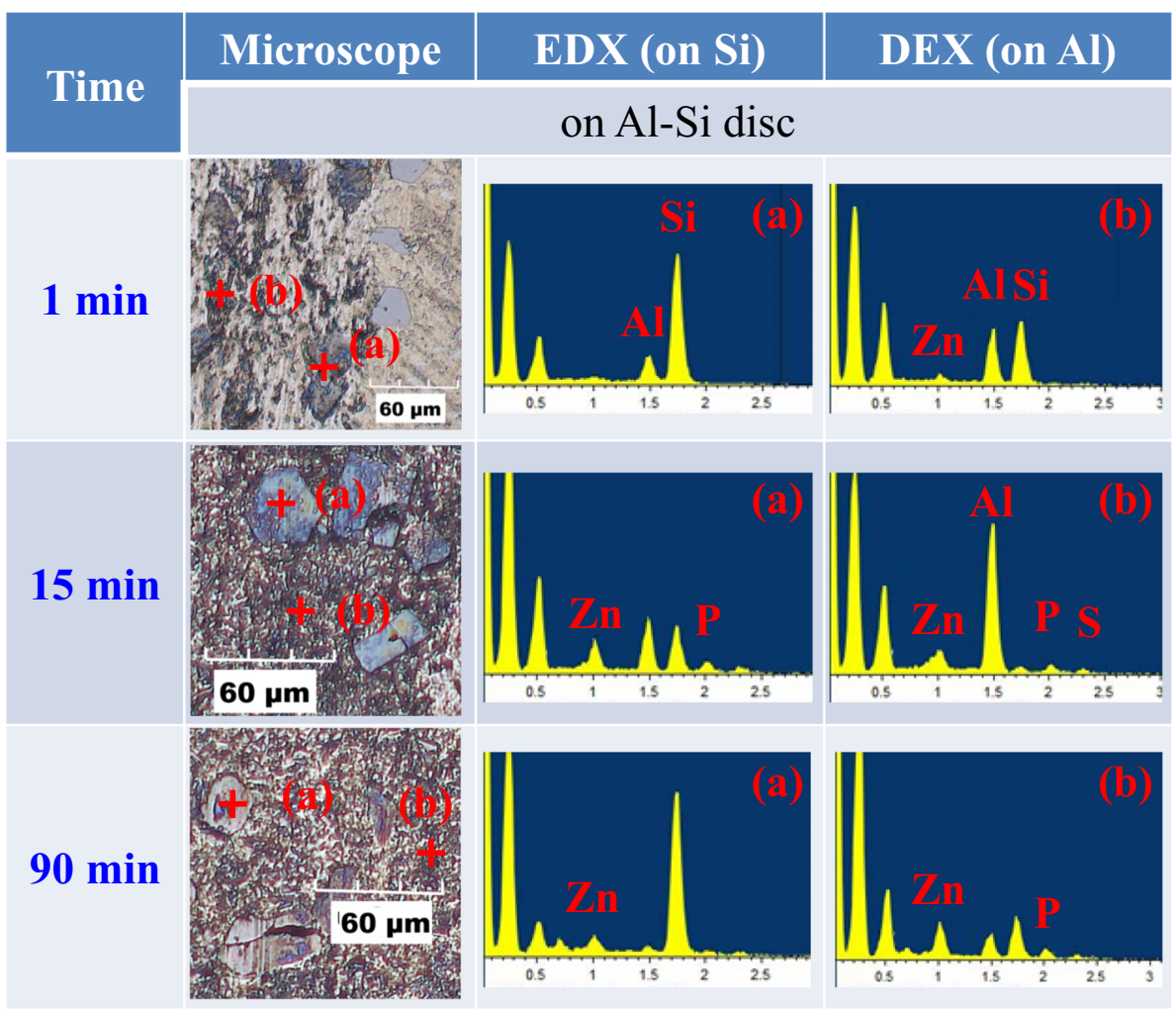



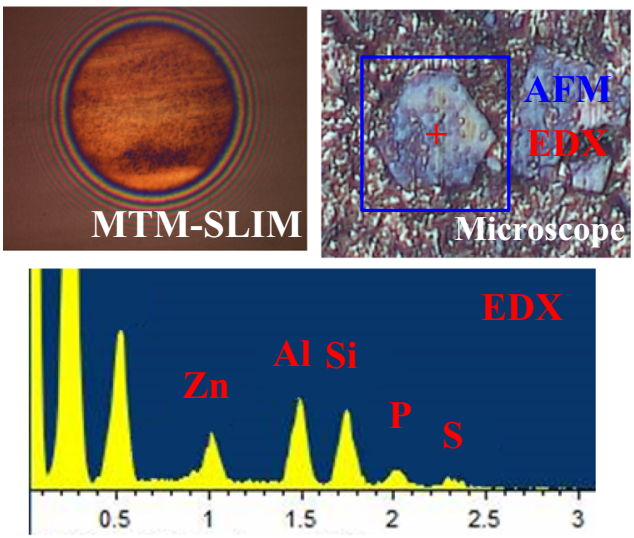

At end of test
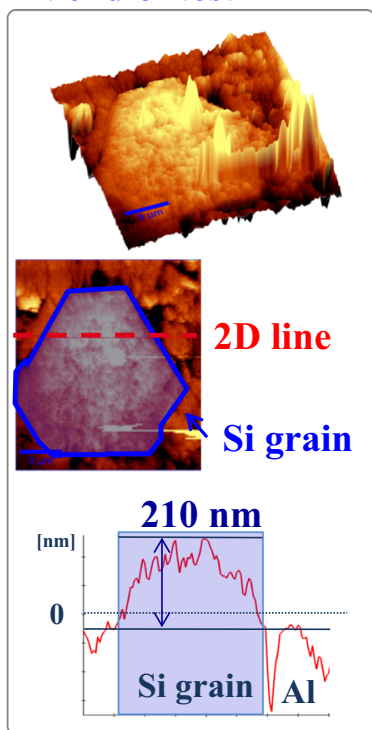

Tribofilms removed by EDTA

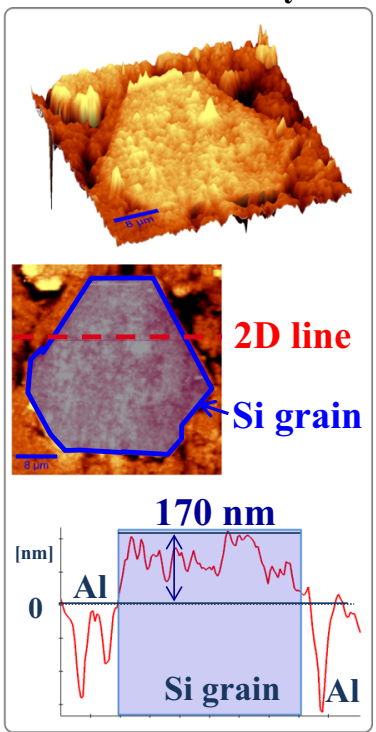

Fig. 17 AFM results of Al-Si disc at $15 \mathrm{~min}$ in $20 \mathrm{~N}, 201 \%$ SRR

Fig. 18 AFM results of $\mathrm{Al}-\mathrm{Si}$ disc at $90 \mathrm{~min}$ in $20 \mathrm{~N}, 201 \%$ SRR; a on the worn track, b across the edge of the worn track (a)

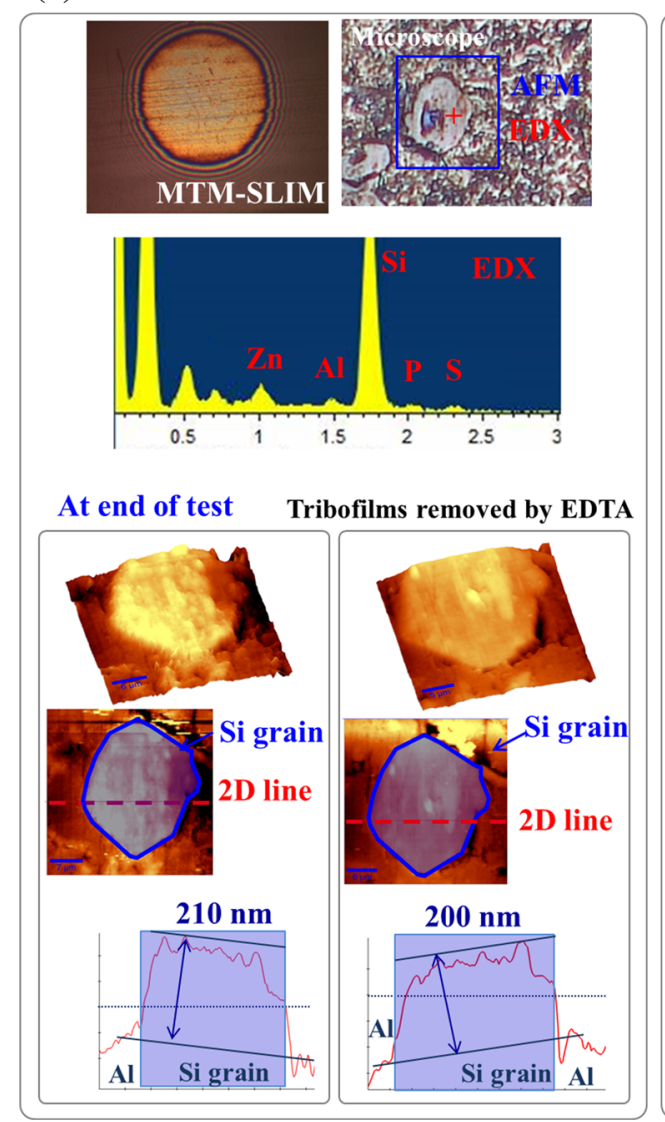

(b)
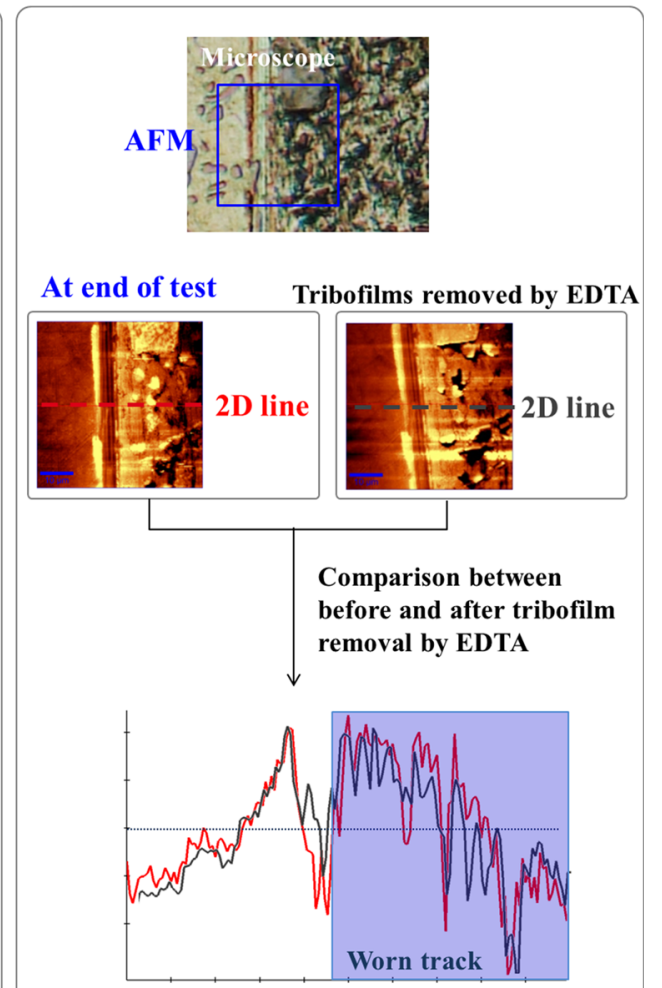

_ Before tribofilm removal

After tribofilm removal 


\subsection{Proposed Model of Tribofilm Build Up on the Al-Si Alloy and the Counter-Surface}

The theoretical minimum EHD film thickness can be estimated from the Dowson-Hamrock elastohydrodynamic lubrication (EHL) equation to be ca $25 \mathrm{~nm}$ at $20 \mathrm{~N}$ load and an entrainment speed of $160 \mathrm{~mm} / \mathrm{s}$. This implies an initial lambda ratio of ca 0.35 . During the rubbing test, the surfaces become rougher, because of both the formation of a ZDDP film and, for $\mathrm{Al}-\mathrm{Si}$, the removal of $\mathrm{Al}$ matrix. Therefore, the tests conducted in this study were always carried out under boundary lubrication conditions.

Based on the results, the following two hypotheses of how tribofilms build up can be suggested in different test conditions (Figs. 19, 20).

At low-load conditions (Fig. 19), the top layer of aluminium on the Al-Si disc is removed physically while silicon grains remain in the surface. ZDDP tribofilm pads are built up on the resulting, protruding silicon grains; this finding is similar to that reported by Nicholls et al. [7]. On steel balls which are counter-surfaces to the Al-Si material, ZDDP tribofilms are formed and build up with the rubbing time and no wear scars are observed on the surface.

At high loads, at the beginning of the test (Fig. 20-2), ZDDP tribofilms are mainly built up on aluminium on the Al-Si disc, and some gaps appear around the silicon grains, presumably due to lateral forces on the grains causing their displacement and consequent deformation of the surrounding Al matrix. Initially, the surface of the aluminium matrix is almost level with the top of the silicon grains and while this is the case, the ZDDP tribofilms are also built up on the counter-surface (steel ball) and there is also transfer of aluminium from the $\mathrm{Al}-\mathrm{Si}$ disc to the steel ball. During further rubbing (Fig. 20-3), ZDDP tribofilms form on both

\section{Before the test}

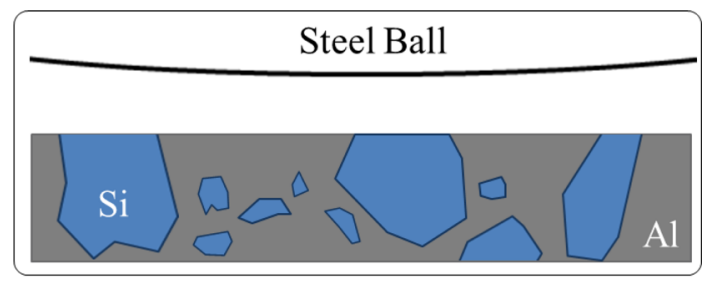

\section{After rubbing test}

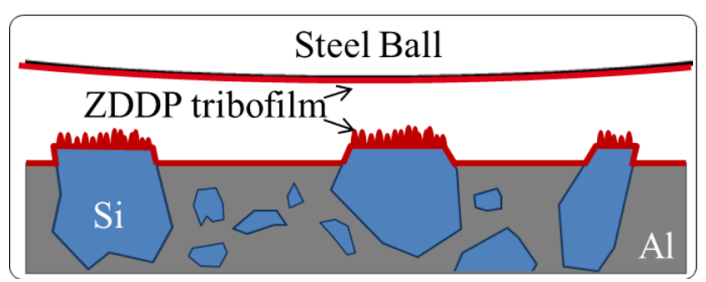

Fig. 19 Hypothesis of how tribofilms build up in low-load conditions
1. Before the test



2. Beginning of the test

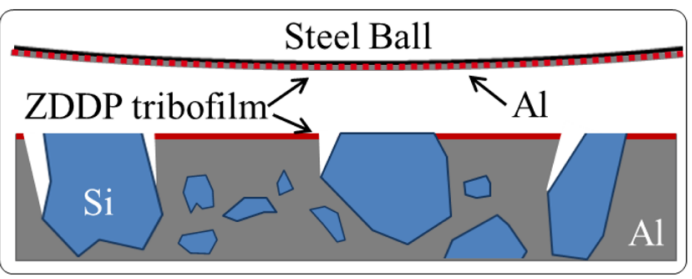

3. Further rubbing test (1)

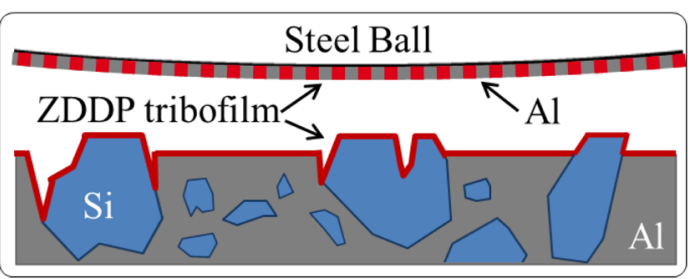

4. Further rubbing test (2)

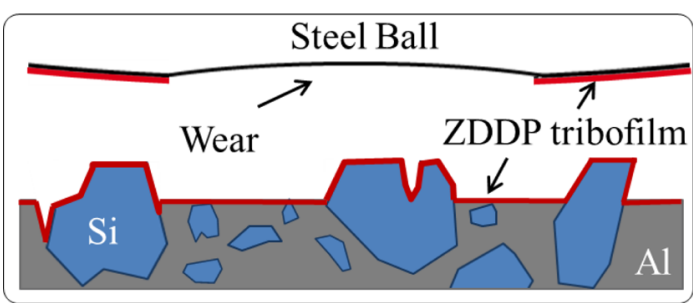

Fig. 20 Hypothesis of how tribofilms build up in high-load conditions

the silicon and aluminium surface; however, the aluminium is removed with rubbing and also some cracks appear on silicon grains. On the steel ball, the ZDDP tribofilm becomes thicker. Finally, after further rubbing test (Fig. 20-4), silicon grains protrude from the aluminium surface because of physical removal of the aluminium and these protruded silicon grains remove the tribofilm from the opposing steel ball, presumably by abrasion. Once the protective tribofilm is removed, wear of the steel ball ensues.

\section{Conclusion}

The authors have investigated the influence of Al-Si alloy on ZDDP tribofilm formation in a steel ball on hypereutectic Al-Si alloy disc in sliding-rolling contact, using the 
MTM-SLIM method and the surface analyses. Key conclusions are as follows.

1. In low-load conditions, the top layer of aluminium on the Al-Si disc is removed physically during rubbing so that silicon grains protrude the surface, and ZDDP tribofilm pads are mainly formed on these grains; this result is consistent with the previous research [7]. On the steel ball counter-surface, ZDDP tribofilms are formed and build up with the rubbing time and appear to fully protect the steel surface against wear.

2. In high-load conditions, deep gaps form initially around the silicon grains of the $\mathrm{Al}-\mathrm{Si}$ disc due to rubbing. After further rubbing time, the depths of these grooves become shallower and the silicon grains start to protrude from the surrounding matrix. On the steel ball, a ZDDP tribofilm is created initially over the whole rubbing track, but as the silicon grains protrude from the counter-surface, they remove the ZDDP film on the steel ball in the middle of the rubbing track where the pressure is highest. Wear of the steel ball is then observed in this region.

Tribofilm formation on Al-Si alloys has been previously researched, and it has been reported that silicon grains protrude from the surface as aluminium is removed physically by rubbing. This study using MTM-SLIM method has shown that these protruded silicon grains can cause the wear on the counter-surface. Recently, new coatings for piston rings have been employed in combination with AlSi alloy cylinder liners. This study may suggest ways to investigate the antiwear performance of novel coatings materials against $\mathrm{Al}-\mathrm{Si}$.

Open Access This article is distributed under the terms of the Creative Commons Attribution 4.0 International License (http://crea tivecommons.org/licenses/by/4.0/), which permits unrestricted use, distribution, and reproduction in any medium, provided you give appropriate credit to the original author(s) and the source, provide a link to the Creative Commons license, and indicate if changes were made.

\section{References}

1. Heywood, J.B., Welling, O.Z.: Trends in performance characteristics of modern automobile SI and diesel engines. SAE Int. J. Engines 2, 1650-1662 (2009)

2. Vora, K.C., Ramdasi, S.S., Walke, N.H., Marathe, A.W., Marathe, N.V.: Development strategy for high specific power low emission diesel engines. SAE technical paper, 2009-26-0020 (2009)

3. Obert, P., Müller, T., Füßer, H.J., Bartel, D.: The influence of oil supply and cylinder liner temperature on friction, wear and scuffing behavior of piston ring cylinder liner contacts-a new model test. Tribol. Int. 94, 306-314 (2016)
4. Haizhi, Y.: An overview of the development of Al-Si-alloy based material for engine applications. J. Mater. Eng. Perform. 12, 288-297 (2003)

5. Raymond, D., Fabiyi, P. A.: Manufacturing feasibility of allaluminum automotive engines via application of high silicon aluminum alloy. SAE technical paper, No. 2000-01-0061 (2000)

6. Peter, K., Kennedy, M., Foss, J.: New aluminum alloys for cylinder liner applications. SAE technical paper, No. 2006-010983 (2006)

7. Nicholls, M.A., Norton, P.R., Bancroft, G.M., Kasrai, M., Stasio, G.D., Wiese, L.M.: Spatially resolved nanoscale chemical and mechanical characterization of ZDDP antiwear films on aluminum-silicon alloys under cylinder/bore wear conditions. Tribol. Lett. 18, 261-278 (2005)

8. Nicholls, M.A., Norton, P.R., Bancroft, G.M., Kasrai, M.: X-ray absorption spectroscopy of tribofilms produced from zinc dialkyl dithiophosphates on Al-Si alloys. Wear 257, 311-328 (2004)

9. Spikes, H.A.: The history and mechanisms of ZDDP. Tribol. Lett. 17, 469-489 (2004)

10. Xia, X., Morina, A., Neville, A., Priest, M., Roshan, R., Warrens, C.P., Payne, M.J.: Tribological performance of an Al-Si alloy lubricated in the boundary regime with zinc dialkyldithiophosphate and molybdenum dithiocarbamate additives. Proc. Inst. Mech. Eng. Part J: J. Eng. Tribol. 222, 305-314 (2008)

11. Spikes, H.A., Cann, P.M.: The development and application of the spacer layer imaging method for measuring lubricant film thickness. Proc. Inst. Mech. Eng. Part J: J. Eng. Tribol. 215, 261-277 (2001)

12. Taylor, L., Dratva, A., Spikes, H.A.: Friction and wear behavior of zinc dialkyldithiophosphate additive. Tribol. Trans. 43, 469-479 (2000)

13. Fujita, H., Spikes, H.A.: The formation of zinc dithiophosphate antiwear films. Proc. Inst. Mech. Eng. Part J: J. Eng. Tribol. 218, 265-278 (2004)

14. Fujita, H., Glovnea, R.P., Spikes, H.A.: Study of zinc dialkydithiophosphate antiwear film formation and removal processes, part I: experimental. Tribol. Trans. 48, 558-566 (2005)

15. Fujita, H., Spikes, H.A.: Study of zinc dialkyldithiophosphate antiwear film formation and removal processes, part II: kinetic model. Tribol. Trans. 48, 567-575 (2005)

16. Ksenija, T.M., Forbus, T.R., Spikes, H.A.: Film thickness and roughness of ZDDP antiwear films. Tribol. Lett. 26, 161-171 (2007)

17. Matthew, S., Hamer, C., Spikes, H.A.: A study of antiwear additive film build up using the MTM (mini-traction machine). In: ASME/STLE 2007 International Joint Tribology Conference. ASME (2007)

18. Miklozic, K.T., Forbus, T.R., Spikes, H.A.: Performance of friction modifiers on ZDDP generated surfaces. Tribol. Trans. 50, 328-335 (2007)

19. Olomolehin, Y., Kapadia, R., Spikes, H.: Antagonistic interaction of antiwear additives and carbon black. Tribol. Lett. 37, 49-58 (2010)

20. Zhang, J., Yamaguchi, E., Spikes, H.: The Antagonism between succinimide dispersants and a secondary zinc dialkyl dithiophosphate. Tribol. Trans. 57, 57-65 (2014)

21. Shimizu, Y., Spikes, H.A.: The influence of slide-roll ratio on ZDDP tribofilm formation. Tribol. Lett. 64, 19 (2016)

22. Shimizu, Y., Spikes, H.A.: The tribofilm formation of ZDDP under reciprocating pure sliding conditions. Tribol. Lett. 64, 46 (2016)

23. Chen, M., Meng-Burany, X., Perry, T.A., Alpas, A.T.: Micromechanisms and mechanics of ultra-mild wear in $\mathrm{Al}-\mathrm{Si}$ alloys. Acta Mater. 56, 5605-5616 (2008)

24. Chen, M., Alpas, A.T.: Ultra-mild wear of a hypereutectic Al$18.5 \mathrm{wt} \%$ Si alloy. Wear 265, 186-195 (2008) 
25. Dey, S.K., Perry, T.A., Alpas, A.T.: Micromechanisms of low load wear in an Al-18.5\% Si alloy. Wear 267, 515-524 (2009)

26. Chen, C.L., Richter, A., Thomson, R.C.: Investigation of mechanical properties of intermetallic phases in multi-component Al-Si alloys using hot-stage nanoindentation. Intermetallics 18, 499-508 (2010)
27. Lombardi, A., D’Elia, F., Ravindran, C., Murty, B.S., MacKay, R.: Analysis of the secondary phases in the microstructure of 319 type Al alloy engine blocks using electron microscopy and nanoindentation. Trans. Indian Inst. Met. 64, 7-11 (2011) 